\section{O QUE PLATÃO DIRIA SE ELE JOGASSE POKEMON GO?}

\author{
Marcia Marciel Ziober \\ Graduanda em Filosofia \\ Universidade de Brasília
}

\section{RESUMO}

Platão pensou sobre a realidade. Como se enquadraria as reflexões de Platão sobre a realidade nos dias de hoje onde pensamos sobre realidade virtual e, mais recentemente, realidade aumentada. É possível analisar estes, podemos dizer, tipos novos de realidade que surgem à luz de Platão?

Palavras-chaves: realidade virtual, realidade aumentada, mimesis, jogo.

\begin{abstract}
Plato thought about reality. How would you fit in Plato's reflections on reality these days where we think about virtual reality and, more recently, augmented reality. Is it possible to analyze these, we may say, new types of reality that arise in the light of Plato?
\end{abstract}

Keywords: virtual reality, augmented reality, mimesis, game.

Esse trabalho pretende apresentar uma análise do jogo Pokemon Go, utilizando as reflexões feitas por Platão nos diálogos $A$
República e $O$ Sofista a respeito da arte como imitação, como mimeses.

O Pokémon Go é um jogo para ser instalado em telefones celulares e que, utilizando-se do $\operatorname{GPS}^{1}$ do celular, simula o mundo real, onde o jogador caça e treina pequenos monstros virtuais como Pikachu e Jigglypuff para que eles lutem uns contra os outros. Esses pequenos monstros, graças à interação com o GPS, aparecem em lugares onde o jogador se encontra.

O sucesso do jogo vem da mistura com a realidade que é apresentada na tela do telefone celular do jogador através da câmera de filmagem presente no mesmo.

O jogador vê o mundo real, ou seja, o local onde ele se encontra, apresentado na câmera do seu telefone, mas recheado de personagens Pokémon.

Esses monstrinhos Pokémon foram apresentados pela primeira vez em 1990, como personagens do Game Boy da Nintendo. Depois se tornaram personagens de desenhos animados e

\footnotetext{
${ }^{1}$ GPS é a sigla para Global Positioning System, que em português significa "Sistema de Posicionamento Global", e consiste numa tecnologia de localização por satélite.O GPS é um sistema de navegação por satélite a partir de um dispositivo móvel, que envia informações sobre a posição de algo em qualquer horário e em qualquer condição climática.
} 
hoje habitam o universo do jogo Pokémon Go. (BBC Brasil, 2016)

O jogo Pokémon Go utiliza-se da realidade virtual e da realidade aumentada. Tanto a realidade virtual como a aumentada são áreas que cuidam da interface do usuário com as aplicações desenvolvidas para computadores. Essas aplicações podem ser jogos, simulações ou treinamento, por exemplo. O objetivo dessas áreas é facilitar e potencializar a interação dos usuários com essas aplicações.

A realidade virtual utiliza representações tridimensionais as mais próximas possíveis da realidade do usuário, o que permite uma interação mais natural. Uma das desvantagens apresentadas da realidade virtual foi a necessidade de utilização de aparelhos, tais como óculos, capacetes, luvas, para que o usuário fosse transportado ao ambiente tridimensional. Esses artefatos não são utilizados no jogo Pokémon Go.

A realidade aumentada é quando, na aplicação, se sobrepõe objetos e ambientes virtuais com o ambiente físico, utilizando de algum dispositivo tecnológico (Kirner e Siscouto, 2007, pg.4-5). No jogo Pokémon Go, a realidade aumentada surge quando, por exemplo, os monstrinhos aparecem no filme que a câmera do celular faz do local real onde o jogador se encontra.

$\mathrm{Na}$ análise do jogo, observamos que o jogo Pokémon Go utiliza mapas fornecidos pelo GPS que mostra onde estão os monstrinhos; a filmagem da câmera do telefone celular quando o usuário se encontra no local onde estão os monstrinhos; e os monstrinhos e suas interações.

A partir da descrição do jogo Pokémon Go, podemos observar vários aspectos apresentados pelo jogo que são passíveis de análise através dos "olhos" de Platão. Conceitos como simulacros, fantasmas, espelhamento da realidade, aparência, afastamento da realidade podem ser observados no jogo.

Segundo Platão, existem três níveis a serem considerados quando pensamos sobre a realidade de um objeto qualquer. O primeiro nível é a Ideia do objeto que representa a realidade, a verdade; o segundo nível é o objeto construído por um artesão a partir da ideia do mesmo e o terceiro nível é a pintura do objeto. Ou seja, um quadro que retrata um carro está no terceiro nível, estando afastados três pontos da realidade do carro.

Platão também divide a mimeses, ou a arte de copiar, em dois tipos: a arte da cópia, também chamada de arte icástica, e a arte do simulacro, 
também chamada de arte fantástica. Segundo ele, a arte da cópia é aquela onde o artista copia fielmente o modelo, seguindo a proporção exata quanto à largura, comprimento e profundidade.

A arte do simulacro ocorre quando 0 artista desfigura essas proporções, substituindo-as por outras proporções que iludem o espectador dando a impressão que as proporções do objeto copiado são proporções verdadeiras. $O$ artista $o$ faz para favorecer os espectadores que estão em posição desfavorável. É o caso de quadros de grandes dimensões que reproduz muitos objetos da realidade (P1. Sph. 235e-236e).

A filmagem do local, para Platão, seria como se fosse um espelho da realidade, ou seja, uma aparência que não tem uma existência real. Platão afirma que um artista poderia fabricar tudo o que existe se ele utilizasse um espelho, ou, nas suas próprias palavras, "num abrir e fechar dos olhos farás o sol e tudo o que há no céu; num segundo, a terra; rapidamente farás a ti mesmo e os outros animais, os móveis, as plantas..."(Pl. R. 596e).

Todavia, isso é apenas aparência, não é a realidade. Considerando os níveis sobre a distância da realidade, podemos colocar que a filmagem do jogo Pokémon Go está a três níveis da realidade, pois assemelha-se a uma pintura. A filmagem é um simulacro, está afastada da realidade e só apresenta uma parte mínima dessa realidade (Pl. R. 598c).

Para Platão, essa filmagem seria a arte do simulacro, ou a arte fantástica, pois as proporções que ocorrem na filmagem não condizem com a realidade reproduzida. Mas, por outro lado, a filmagem mostra a realidade como ela se apresenta, só que em tamanho reduzido. Não existe um intermediário, ou seja, o artista que altera as proporções dessa realidade para proporcionar a ilusão de uma realidade verdadeira.

Os mapas fornecidos pelo GPS também se enquadram nessa categoria de arte fantástica, pois apresentam um simulacro da realidade que foi mapeada pelos satélites. Nesse caso, diferente da filmagem, o mapa não mostra a realidade em proporção menor; o simulacro da realidade apresentado é totalmente desfigurado, não tendo intenção de repor a realidade. Pensando desta maneira, o mapa estaria mais afastado da realidade do que a filmagem.

Os monstrinhos que interagem no jogo estão completamente afastados da realidade. Não é possível nem determinar, tendo em vista os níveis de 
afastamento da realidade colocados por Platão, em quantos pontos os monstrinhos estão afastados da realidade. Então qual seria a finalidade desses monstrinhos se não simulam algo real?

Segundo Platão, a mimeses ou a as artes imitativas se encontram muito longe da verdade e acionam a parte da nossa alma mais afastada da razão, uma parte de nossa alma que é conflituosa, que não é sã e nem verdadeira (Pl. R. 603b).

Os monstrinhos no jogo teriam, então, essa finalidade descrita: a de acionar a parte mais conflituosa da nossa alma. Pois, através dos monstrinhos, podemos sentir que somos poderosos quando ganhamos lutas que não são reais, e entristecidos quando não conseguimos a vitória. Mas, tudo isso é ilusão, não é real.

O jogo como um todo tem essa finalidade de iludir, mas é no monstrinho Pokémon que essa parte da nossa alma é acionada, pois os outros dois elementos, os mapas e as filmagens, também acionam a parte da razão quando permitem a localização de determinado monstrinho Pokémon através do mapa e também quando mostram uma realidade alterada, onde o monstrinho se insere na filmagem do local do usuário, fornecida por uma tecnologia que, em minha opinião, se conecta mais à razão do que ao emocional.

Um papel importante no jogo é aquele que é representado pelo usuário. Na teoria de Platão existem três tipos de artes: "a que se serve delas, a que fabrica e a que a imita" (Pl. R. 601d).

Ao pensar no jogo como um todo e não analisando suas partes separadamente, podemos considerar o usuário do jogo Pokémon Go como aquele que se serve das artes, pois ele tem mais experiência e condições para orientar o fabricante do jogo quanto às qualidades e os defeitos do mesmo; pois, através do uso, o jogador tem condições de revelar esses defeitos e qualidades (Pl. R. 601e). É o usuário que detém o conhecimento, a ciência do jogo (Pl. R. 601e-602a).

O desenvolvedor do produto, os programadores e não o fabricante, é quem fabrica a arte, pois, utilizando a opinião do usuário, pode aperfeiçoar o jogo. É quem forma a opinião certa sobre o produto (Pl. R. 602a). A imitação do jogo, semelhante ao quadro do pintor, seria uma filmagem ou fotografia, por exemplo, de um jogador em ação. 
Considerações Finais

A análise do jogo Pokémon Go através da visão de Platão demonstra que as reflexões que ele fez da arte em seus diversos aspectos podem ser aplicadas a qualquer objeto construído pelo homem.

A busca de Platão pela realidade ou verdade pode ainda ser trabalhada nas múltiplas realidades que se apresentam no nosso mundo contemporâneo, onde encontramos aplicações computacionais sofisticadas que podem, com mais força, enganar os nossos sentidos, e, pior, o nosso cérebro.

A pergunta que fica é: porque precisamos dessa ilusão construída para enganar nossos sentidos? $\mathrm{O}$ homem atual não suporta a realidade que se mostra e, então, precisa criar uma que lhe agrada mais? Ou ainda, por que será que preenchemos todo o nosso tempo livre, um tempo que é precioso, com simulacros de vida real?

Se Platão estivesse entre nós talvez fizesse essas perguntas e outras mais, e nós, aguardaríamos ansiosos as suas análises e respostas.
Referências Bibliográficas

BBC Brasil. 2016. O que é Pokémon Go e por que está causando tanto furor no mundo dos games? Disponível em: http://www.bbc.com/portuguese/geral36802725. Acessado em 28/06/2017 09h13min.

Disponível em www.significados.com.br. Acessado em 28/06/2017 09h15min.

KIRNER, C. \& SISCOUTO, R. ed. (2007). Realidade virtual aumentada. 15. Porto Alegre, Editora SBC Sociedade Brasileira de Computação.

NUNES, C. A. 2000. Platão. A república (tradução). 3.ed. Belém: EDUFPA.

PALEIKAT, J. e COSTA, J. C. (1972) Platão. Sofista (tradução). São Paulo, Abril. 